\title{
Knowledge, Attitude, and Practice about CPR and Associated Factors among Laypersons in Dammam, Riyadh, and Jeddah
}

\author{
Basam Hassan Aljewayed ${ }^{1, *}$, Nadeer Zaki Albaik2 ${ }^{2}$, Hussein Saleem Aljuwayed ${ }^{3}$, \\ Faris Hassan Saleem Aljewayed ${ }^{4}$, Seraj Zaki Albaik ${ }^{5}$, Mohammed Abbas AlQarous ${ }^{2}$ \\ and Jaffar Mohammed Alshorafa ${ }^{2}$ \\ 1Arabian Gulf University, Bahrain, Saudi Arabia; Aljewayed.bh@gmail.com \\ 2Imam Abdulrahman Bin Faisal University, Dammam, \\ Saudi Arabia; nadeer.albaik@gmail.com, \\ maq-4000@hotmail.com, jaf2006r@gmail.com \\ 3Prince Sultan Military Medical City, Riyadh, Saudi Arabia; Juwayedh@gmail.com \\ 4King Saud Medical City, Riyadh, Saudi Arabia; Fa7fa17@gmail.com \\ 5Salwa General Hospital, Dammam, Saudi Arabia; Albaik27@gmail.com
}

\begin{abstract}
Background: Cardio-Pulmonary Resuscitation (CPR) is a crucial life-saving skill that should be taught to all members of the community. Objectives: To evaluate the knowledge, attitude, and practice about CPR and associated factors among laypersons. Materials and methods: A cross-sectional study that was done among layperson in Dammam, Riyadh, and Jeddah. Among 527 participants, 364 (69\%) were male, and 163 (31\%) were female. Most of our participants 472 (89.6\%) did not receive CPR training while the remaining 55 (10.4\%) received the CPR training. Results: Our results reveal that a significant correlation exists between education level and the CPR training received. The participants with a higher educational level are significantly higher among participants who received the training. Conclusions: Layperson CPR training rate in the study area (Dammam, Riyadh, and Jeddah) less common than in many developed countries.
\end{abstract}

\section{Introduction}

According to the Institute for Health Metrics and Evaluation, ischemic heart disease is the number one cause of death in Saudi Arabia. $\frac{1}{}$ About $46 \%$ of the deaths are due to cardiovascular diseases. $\underline{\underline{2}}$

$\mathrm{CPR}$ is a lifesaving technique for critical emergencies, including heart attack or near drowning, in which someone's breathing or heartbeat has stopped. Early introduction of CPR can enhance patient survival and neurologic outcome. Targeted education on CPR for emergency care providers and the public has improved the survival rate of the patients. $\underline{3}$

A report from the American Heart Association demonstrated that $79 \%$ of thelay public were confident that they know what actions to take in a medical emergency. Ninety-eight percent (98\%) of the participants recognized an automated external defibrillator as something that administers an electric shock to return a normal heartbeat among victims of unexpected cardiac arrest, and $60 \%$ were familiar with cardiopulmonary resuscitation. $\underline{4}^{4}$

A 2017 study in China found that $90 \%$ of laypersons understood what CPR is. Twenty-five percent (25\%) of the laypersons were trained in different kinds of CPR courses. Thirteen percent (13\%) of laypersons knew the standard $\mathrm{CPR}$ procedure and believed they could perform CPR The primary reason for the layperson not learning CPR was that they did not know where to find a CPR training course. However, in China, layperson CPR training and

${ }^{*}$ Author for correspondence 
bystander CPR rate are still less common than in many developed countries. .5

A 2015 study in Sultan Oman found that 54.8\% of participants indicated that they do not know how to perform CPR. More worrying, 59.9\% believed that CPR has no role in a situation where a child has chocked and became unconscious. 6

A 2015 study in Riyadh discovered 74\% of arrests occurred at home, confirmed a low rate of bystander CPR being performed during out-of-hospital, and showed that bystander CPR was performed on $25 \%$ of the outof-hospital traumatic arrests compared to $20.2 \%$ of nontraumatic arrests. $\underline{7}$ This knowledge, attitude, and practice of this essential skill were not studied in all layperson categories. The aim of this study is to evaluate knowledge, attitude, and practice about CPR and associated factors among laypersons in the three main cities in Saudi Arabia (Riyadh, Jeddah, and Dammam).

\section{Material and Method}

The cross-sectional study was done among layperson in Dammam, Riyadh, and Jeddah during the period of September 2017 and October 2017, using a selfadministrated validated questionnaire to assess the knowledge, attitude, and practice about CPR and associated factors among laypersons.

Face validity was done by two consultants, and then pilot study was done on 32 questionnaires.

Data collection was done by the researcher using a questionnaire, which contained four sections. The first section included questions about the CPR for laypersons who have not received CPR course. The second and third sections were designed for laypersons who received CPR course and they included questions regarding the course (date, period, the cost, and the place of the course) and questions about the CPR, respectively. The fourth section included demographic data; age, sex, marital status, income level, number of children, level of education, employment details, residence, and history of any disease.

Data collection was done on public places: parks, malls, and coffee shops in Dammam, Riyadh, and Jeddah. The target population were 18 years of age or older, both genders, and non-healthcare professionals (laypersons). A total of 527 laypersons responded to our questionnaire.

\section{Statistical Method}

Data were analysed using SPSS software version 16 , the simple descriptive analysis in the form of numbers and percent for qualitative variables; mean and standard deviation for quantitative variables. Chi-square was used as a test of significance to compare qualitative variables between trained and untrained group, with a significant level of less than 0.05 .

\section{Results}

A total of 527 laypersons in Dammam, Riyadh, and Jeddah responded to our questionnaire.

\subsection{Demographic Data}

Among all the participants, 364 (69\%) were male, and 163 (31\%) were female. A total of $414(78.5 \%)$ were living in an urban environment, and 113 (21.5\%) were living in a rural environment. Regarding the marital status, 261 (49.5\%) were singles, $251(47.6 \%)$ were married, 11 (2\%) were widow, and $4(0.8 \%)$ were divorced. The educational levels of the participants were as follows; $46(8.7 \%)$ were illiterate, $53(10 \%)$ had primary school education, $36(6.8 \%)$ had intermediate school education, 189 (35.9\%) had secondary school education, 191 (36.2\%) had university education level, and 12 (2.3\%) were postgraduates. Most participants 343 (65.1\%) had intermediate income, 152 (28.8\%) had low income, and 32 (6.1\%) had the high income. Regarding history of chronic diseases; 60 participants (11.4\%) had joints pain, 40 (7.6\%) had hypertension, 20 (3.8\%) had diabetes mellitus, 15 (2.8\%) had hypercholesterolemia, and $12(2.3 \%)$ had heart disease.

\subsection{Distribution of the Participants among the Two Studied Groups}

Most of the participants (89.6\%) did not receive CPR training (Table 1).

\subsection{The Knowledge about CPR among Participant Who Did Not Receive the Training}

This part of the questionnaire consisted of seven questions concerned only with participants who did not receive the CPR training. Analysis of these questions demonstrated that $39.2 \%$ of the participants thought that the nearest one to the person who is unconscious in a public place 
Table 1. Status of participants

\begin{tabular}{|l|l|l|}
\hline & N & \% \\
\hline Receiving training & 55 & 10.4 \\
\hline Not receiving training & 472 & 89.6 \\
\hline
\end{tabular}

should deal with him/her, while $35.5 \%$ directed the task to medical workers available in the location. The remaining participants believed that ambulance or police should be responsible (16.7\% and 9.5\%, respectively). Most of the participants (61.9\%) who did not receive the training preferred to call the ambulance when they see an unconscious person. Around two-thirds (66.3\%) of this group of participants would not deal with a person who is unconscious, whereas $72.9 \%$ of them hadn't sufficient knowledge to deal with such cases. Most of them (81.9\%) thought that the drowning cases would have the largest benefit from the CPR technique, as compared to $32.2 \%$ for snorkeling with food, $26.3 \%$ for defects in breathing among children, $16.1 \%$ for burns, $12.5 \%$ for pregnant women, $11.02 \%$ for the old age cases, $6.4 \%$ for stroke patients, 5.5\% for angina patients, and 3.4\% in accidents. Around three quarters (73.1\%) of participants thought that anyone could learn how to deal correctly with CPR persons and $83.6 \%$ of them reasoned their lack of training due to time constraints (Table 2).

\subsection{The Details of CPR Training Received by Our Participants}

As mentioned above, only $55(10.4 \%)$ participants received the CPR training, $72.7 \%$ of who received it during the period from 2011 to 2017, 18.1\% before 2000 and $0.1 \%$ from 2000 to 2010 . Around one-third of the participants (32.6\%) received their training in hospitals and medical centers, $12.5 \%$ in ARAMCO, $10.9 \%$ in charge. Five participants $(9.1 \%)$ received their training in each of the following cities; Jeddah, Dammam, Hail, and Faraby, while only $3.6 \%$ received their training in $\mathrm{Al}$ Madina Al Munawwarah.

Regarding the training cost, $40 \%$ had received the CPR training for free, $38.2 \%$ paid from 1 to 100 SR, and the remaining $21.8 \%$ paid more than 100 SR. Only $9.1 \%$ of participants rated the cost as high, as compared to $41.8 \%$ who rated it as cheap, and $49.1 \%$ who rated it as average. Training duration was only one day among $20 \%$ of the participants, while it was one week among $36.4 \%$ of the participants. In addition, it took two weeks to train $40 \%$ of the participants, and two months to train the remaining $3.6 \%$ of them. More than half of the participants (52.4\%) mentioned that they did not need to apply what they learned in the CPR training, while the remaining $47.3 \%$ mentioned that they applied it. Those who actually performed resuscitation accounted for $46.2 \%$, as compared to $43.7 \%$ who did not.

\subsection{The Reaction of Participants Who Received the CPR Training Toward CPR Cases}

More than half of participants (58.2\%), who received CPR training, would call the ambulance if they encounter unconscious case, as compared to $18.2 \%$ who would start resuscitation, $16.4 \%$ who would transfer the patient to the nearest hospital, and $7.3 \%$ who chose to do nothing. Almost half of the participants (45.5\%) thought that the carotid method shall be used to assess pulsation, as compared to $18.2 \%$ and $16.4 \%$ who thought that the radial and brachial arteries (respectively) shall be used instead. The remaining 20\% through using stethoscope was the appropriate method.

When they were asked about Heimlich maneuver, 58.2\% thought it was used in case of difficulties of breathing, and $41.8 \%$ thought it was used in the stroke cases. $70.9 \%$ of our participants through $75 \%$ of CPR cases would be rescued, $18.2 \%$ through $90 \%$ and 10.9 through $25 \%$. Most participants believed that raising awareness about CPR should be through obligatory training/education (56.4\% obligatory for students, and $21.8 \%$ obligatory for employees). On the other hand, $34.5 \%$ believed that free courses shall be offered, $36.4 \%$ believed that courses shall be increased in number, $20 \%$ thought it should be though education, $9.1 \%$ though receiving private courses and $18.2 \%$ thought granting financial incentives after receiving the CPR training might encourage people to participate in it.

\subsection{Comparison Between Those Receiving and Not Receiving Training}

The correlation between residence and education, on the one hand, and having received CPR training, on the other hand, was statistically significant $(P<0.001$ and $P=$ 0.002 , respectively). However, the correlation between sex and income, on the one hand, and having received CPR training, on the other hand, was statistically insignificant $(P=0.115$ and 0.355$)$. 
Table 2. The knowledge about CPR among participant who did not receive the training

\begin{tabular}{|c|c|c|c|}
\hline & & $\mathrm{N}$ & $\%$ \\
\hline \multirow{4}{*}{$\begin{array}{l}\text { Q1: Who is responsible for a person } \\
\text { who is unconscious in a public place? }\end{array}$} & Medical workers near the case & 163 & 34.5 \\
\hline & Police & 45 & 9.5 \\
\hline & Ambulance & 79 & 16.7 \\
\hline & The nearest person & 185 & 39.2 \\
\hline \multirow{4}{*}{$\begin{array}{l}\text { Q2: What would you do if you saw } \\
\text { someone with loss of consciousness? }\end{array}$} & Transfer the patient to the hospital & 34 & 7.2 \\
\hline & Calling the ambulance & 292 & 61.9 \\
\hline & Deal with the patient & 117 & 24.8 \\
\hline & Nothing & 29 & 6.1 \\
\hline \multirow{2}{*}{$\begin{array}{l}\text { Q3: Have you had to deal with someone } \\
\text { who is unconscious? }\end{array}$} & Yes $^{\mathrm{a}}$ & 159 & 33.7 \\
\hline & No & 313 & 66.3 \\
\hline \multirow[t]{2}{*}{ Q4: Have you resuscitated? } & Yes & 54 & 33.5 \\
\hline & $\mathrm{No}^{\mathrm{a}}$ & 107 & 66.5 \\
\hline \multirow[t]{3}{*}{ Why not } & Fear of infection & 18 & 16.8 \\
\hline & $\begin{array}{l}\text { Lack of knowledge of how to resuscitate } \\
\text { the patient }\end{array}$ & 78 & 72.9 \\
\hline & Worry & 11 & 10.3 \\
\hline \multirow[t]{9}{*}{ Q5: Cases benefit ${ }^{\mathrm{a}}$ from CPR } & Drowning & 387 & 81.9 \\
\hline & Stroke & 30 & 6.4 \\
\hline & Pregnant & 59 & 12.5 \\
\hline & Food & 152 & 32.2 \\
\hline & Child & 124 & 26.3 \\
\hline & Old age & 52 & 11.02 \\
\hline & Burning & 76 & 16.1 \\
\hline & Angina & 26 & 5.5 \\
\hline & Accident & 16 & 3.4 \\
\hline \multirow{2}{*}{$\begin{array}{l}\text { Q6: Do you know that anyone can learn } \\
\text { how to deal correctly with CPR persons? }\end{array}$} & Yes & 345 & 73.1 \\
\hline & No & 127 & 26.9 \\
\hline \multirow{2}{*}{$\begin{array}{l}\text { Q7: Why you don't want to receive CPR } \\
\text { training? }\end{array}$} & No time & 102 & 83.6 \\
\hline & Leave for specialist & 17 & 16.4 \\
\hline
\end{tabular}

${ }^{\mathrm{a}}$ More than one answer is allowed.

\section{Discussion}

In 2015, the latest highlights of the American Heart Association Guidelines Update for Cardiopulmonary Resuscitation (CPR) and Emergency Cardiovascular Care CPR guidelines were released. $\underline{8}$

Several studies have discussed awareness, knowledge, and attitude about CPR training among health care workers, university students, and teachers $\underline{\underline{9}-11}$; however, to our knowledge, only one study, conducted in Al-Khobar city, had focused on public awareness but it was among children. $\underline{12}$ Our study is concerned with the knowledge and awareness about CPR and CPR training among adult laypersons in Dammam, Riyadh, and Jeddah.

In our study, the proportion of participants who had received CPR training was only $10.4 \%$. This result was in line with a study conducted in Hong Kong by Cheung et al. $\underline{13}$ which only $12 \%$ of interviewees had received the CPR training, while the American Heart Association suggested that at least $20 \%$ of adults need to be trained in CPR before morbidity and mortality from out-of-hospital arrest can be reduced substantially. $\underline{14}$ CPR training rates in other countries were as follows: $27 \%$ in New Zealand, $28 \%$ in Ireland, 35\% in Japan, 58\% in Australia, 64.1\% in West 
Australia, $75 \%$ in Poland, and $79 \%$ in Washington. $\underline{15}-\underline{19}$ These rates vary in the urban and rural regions of the countries. Although in our study most population was from urban communities (78.5\%), the training rate was low, which reflects that the knowledge and awareness about the importance of CPR were low.

By comparing the response of our participants toward how to deal with CPR cases among the two groups, it was found that the percentage of participants who start to deal with the case was higher among people who did not receive the training $(24.8 \%)$ than those who received the training (18.2\%).

Our results reported a significant correlation between education level and receiving the CPR training among the two studied groups where the participants with higher educational level were significantly higher among participants who received the training, these results were similar to those of who reported that the people with a higher educational level has higher knowledge and awareness about CPR than others. In addition, the results matched results which stated that according to Özbilgin et al. $\underline{20}$ the results obtained from a population having a high level of education in the western region of Turkey, the rate of people who received CPR training was found to be $40.3 \%$.

This study showed that the primary reasons for a layperson not attending the CPR training courses were a lack of time and concern, the cost was not considered to be a major problem to learn CPR by the respondents where $40 \%$ of them received the training for free. The reasons for not taking CPR training courses were the same as those noted in China and Belgium. .11

These reports indicated that compulsory CPR training organized by the government was recommended to be added to students and employees, as well as offering free courses. These recommendations were also suggested by Selby et al. $\underline{14}$ for bystanders to perform CPR in China, which had been established many years ago in Norway, United States, Japan, and Slovenia who are good performers of bystander CPR.

\section{Conclusion}

Layperson CPR training rate in the study area (Dammam, Riyadh, and Jeddah) is less common than many developed countries. The barriers included the lack of laypersons' training and knowledge of how to resuscitate patients. As the education level increases, the knowledge about CPR training increased. The majority of participants who received the training belonged to the medical field. The presentation of free courses and compulsory CPR training to students and employees is recommended to increase awareness and knowledge about CPR.

\section{References}

1. The Global Health Data Exchange (GHDx) supported by Institute for Health Metrics and Evaluation. [cited 2019]. http://www.healthdata.org/saudi-arabia.

2. World Health Organization - noncommunicable diseases (NCD) country profiles: Saudi Arabia. [cited 2018]. http:// www.who.int/nmh/countries/sau_en.pdf.

3. Weisfeldt ML. Public access defibrillation: good or great? BMJ Br Med J. 2004;328(7438):271.

4. Statements AS. Heart disease and stroke statistics 2013 update. Circulation. 2013;127(1):245.

5. Chen M, Wang Y, Li X, Hou L, Wang Y, Liu J, Han F. Public knowledge and attitudes towards bystander cardiopulmonary resuscitation in China. BioMed Res Int. 2017;2017:1-7.

6. Al Shaqsi S, Al Wahaibi K, Al Risi A. Wasted potential: awareness of basic cardiopulmonary resuscitation in the Sultanate of Oman-a cross-sectional national survey. J Emerg Med Intens Care. 2015;1(1):105.

7. Salleeh HM, Gabralla KA, Leggio WJ, Al Aseri ZA. Outof-hospital adult cardiac arrests in a university hospital in central Saudi Arabia. Saudi Med J. 2015;36(9):1071.

8. Neumar RW, Shuster CM, Callaway CW. American Heart Association. Highlights of the 2015 American Heart Association guidelines update for cardiopulmonary resuscitation $(\mathrm{CPR})$ and emergency cardiovascular care (ECC). 2015;132(2):1-53.

9. Al-Turki YA, Al-Fraih YS, Jalaly JB, Al-Maghlouth IA, Al-Rashoudi FH, Al-Otaibi AF, Al-Thnayan AA, Trabzon AI, Al-Shaykh AS. Knowledge and attitudes towards cardiopulmonary resuscitation among university students in Riyadh, Saudi Arabia. Saudi Med J. 2008;29(9): 1306-09.

10. Alharbi MM, Horaib YF, Almutairi OM, Alsuaidan BH, Alghoraibi MS, Alhadeedi FH, et al. Exploring the extent of knowledge of CPR skills among school teachers in Riyadh, KSA. J Taibah Univ Med Sci. 2016;11(5):497-501.

11. Abolfotouh MA, Alnasser MA, Berhanu AN, Al-Turaif DA, Alfayez AI. Impact of basic life-support training on the attitudes of health-care workers toward cardiopulmonary resuscitation and defibrillation. BMC Health Serv Res 2017;17(1):674.

12. Al-Turkistani HK. Awareness and knowledge of pediatric cardiopulmonary resuscitation in the community of Al-Khobar city. J Fam Community Med. 2014;21(2):125. 
13. Cheung BM, Ho C, Kou KO, Kuong EE, Lai KW, Leow PL. The University of Hong Kong Cardiopulmonary Resuscitation Knowledge Study Group. Knowledge of cardiopulmonary resuscitation among the public in Hong Kong: telephone questionnaire survey. Hong Kong Med J. 2003;9(5):323-8.

14. Selby ML, Kautz JA, Moore TJ, Gombeski Jr WR, Ramirez AG, Farge EJ, et al. Indicators of response to a mass media CPR recruitment campaign. Am J Public Health. 1982;72(9):1039-42.

15. Larsen P, Pearson J, Galletly D. Knowledge and attitudes towards cardiopulmonary resuscitation in the community. N Z Med J (Online). 2004;117(1193).

16. Jennings S, Hara TO, Cavanagh B, Bennett K. A national survey of the prevalence of cardiopulmonary resuscitation training and knowledge of the emergency number in Ireland. Resuscitation. 2009;80(9):1039-42.
17. Kuramoto N, Morimoto T, Kubota Y, Maeda Y, Seki S, Takada K, et al. Public perception of and willingness to perform bystander CPR in Japan. Resuscitation. 2008;79(3):475-81.

18. Celenza T, Gennat HC, O’Brien D, Jacobs IG, Lynch DM, Jelinek GA. Community competence in cardiopulmonary resuscitation. Resuscitation. 2002;55(2):157-65.

19. Sipsma K, Stubbs BA, Plourde M. Training rates and willingness to perform CPR in King County, Washington: a community survey. Resuscitation. 2011;82(5):564-7.

20. Özbilgin Ş, Akan M, Hancı V, Aygün C, Kuvaki B. Evaluation of public awareness, knowledge and attitudes about cardiopulmonary resuscitation: report of İzmir. Turk J Anaesthesiol Reanim. 2015;43(6):396.

21. Mpotos N, Vekeman E, Monsieurs K, Derese A, Valcke M. Knowledge and willingness to teach cardiopulmonary resuscitation: a survey amongst 4273 teachers. Resuscitation. 2013;84(4):496-500. 